\title{
In vitro antioxidant activity and potential inhibitory action against a-glucosidase of polysaccharides from fruit peel of tea (Camellia sinensis L.)
}

\author{
Yue-fei $\mathrm{WANG}^{1,2}$, Jie $W A N G^{1}$, Jing $\mathrm{WU}^{1}$, Ping $\mathrm{XU}^{\dagger 1,2}$, Yi-qi $W A N G^{3}$, \\ Jun-jie GAO ${ }^{1}$, Danielle HOCHSTETTER ${ }^{1}$ \\ ( ${ }^{1}$ Department of Tea Science, Zhejiang University, Hangzhou 310058, China) \\ $\left({ }^{2}\right.$ Key Laboratory of Horticultural Plant Growth, Development and Quality Improvement, Ministry of Agriculture, Hangzhou 310058, China) \\ $\left({ }^{3}\right.$ College of Pharmacy, Zhejiang Chinese Medical University, Hangzhou 310053, China) \\ †E-mail: zdxp@zju.edu.cn
}

Received July 11, 2013; Revision accepted Sept. 11, 2013; Crosschecked Jan. 16, 2014

\begin{abstract}
The conditions for extracting polysaccharides from tea (Camellia sinensis L.) fruit peel (TFPPs) were studied. Three parameters (temperature, time, and liquid/solid ratio) affecting the extraction of TFPP were optimized using response surface methodology (RSM). Under the optimized conditions, the yield of TFPP was predicted to be $4.98 \%$. The physicochemical properties, in vitro antioxidant activities, and inhibitory effects on a-glucosidase of fractionated TFPPs (TFPP-0, TFPP-20, TFPP-40, and TFPP-60) were investigated. We found that the TFPPs were all acid protein-bound heteropolysaccharides, although with different chemical compositions. They had not only remarkable scavenging activity on 2,2'-azinobis(3-ethylbenzothiazoline-6-sulfonic acid) diammonium salt (ABTS) and reducing activity, but also excellent inhibitory potential against $\alpha$-glucosidase in vitro. Our results suggest that tea fruit peel could be treated as a potential bioresource for the development of polysaccharide antioxidants.
\end{abstract}

Key words: Polysaccharides, Tea (Camellia sinensis L.) fruit peel, Physicochemical properties, Antioxidant activity, a-Glucosidase inhibition doi: 10.1631 jzus.B1300186

Document code: A

CLC number: S609.9

\section{Introduction}

Free radicals are not only closely associated with lipid peroxidation, but also involved in the development of a variety of diseases, including cellular aging, mutagenesis, carcinogenesis, coronary heart disease, diabetes, and neurodegeneration (Moskovitz et al., 2002). Antioxidants, which can inhibit or delay the oxidation of an oxidizable substrate in a chain reac-

\footnotetext{
Corresponding author

"Project supported by the Ministry of Science and Technology of China (No. 2012BAD36B06-5)

\#Electronic supplementary materials: The online version of this article (http://dx.doi.org/10.1631/jzus.B1300186) contains supplementary materials, which are available to authorized users

(c) Zhejiang University and Springer-Verlag Berlin Heidelberg 2014
}

tion, would therefore seem to be very important in the prevention of these diseases (Praticò and Delanty, 2000). However, although synthetic antioxidants are widely used, their side effects are of the public concern (Grice, 1988). Thus, there has been increasing interest in finding natural, effective, and safe antioxidants, since they may protect the human body from free radicals and retard the progress of many chronic diseases. A review of the literature shows that polysaccharides derived from plants, such as Pteridium aquilinum (Xu et al., 2009), Ficus carica L. (Yang et al., 2009), Lycium barbarum L. (Lin et al., 2009), and Portulaca oleracea L. (Chen et al., 2009) have remarkable antioxidant activity. Meanwhile, the hypoglycemic effect of polysaccharides from plants, particularly the inhibition of postprandial hyperglycemia, 
has been highlighted recently (Zhu et al., 2013). Furthermore, their potential inhibitory action against $\alpha$-glucosidase has been proposed as one of the main mechanisms responsible for this hypoglycemic effect (Wang et al., 2012).

Tea (Camellia sinensis L.) fruit peel is the main byproduct of the production of tea seed oil, which has long been recognized as an edible oil of high quality. As a result of the increasing popularity of tea seed oil, the yield of tea fruit peel has also increased. However, most tea fruit peel is discarded as industrial waste, resulting in loss of a valuable resource and environmental pollution. Nowadays, recovery of bioactive compounds, including polysaccharides, from food processing wastes is attracting increasing attention as a potentially cheap and reliable source of new and efficient natural antioxidants (Xu et al., 2012; Çam and Aaby, 2010). The extraction and bioactivities of polysaccharides from the seeds of Plantago asiatica $\mathrm{L}$. (Ye et al., 2011), the fruit shell of Camellia oleifera Abel (Shen et al., 2010), and the seabuckthorn pericarp (Ma et al., 2011) have been reported. However, to the best of our knowledge, little information is available about the polysaccharides from tea fruit peel (TFPPs).

The objectives of this study were to optimize the conditions for extracting polysaccharides from tea fruit peel by response surface methodology (RSM), and to fractionate the polysaccharides using graded ethanol precipitation. The physicochemical properties and in vitro activities, including the antioxidant activity and inhibitory potential against $\alpha$-glucosidase, of the fractionated polysaccharides were also investigated.

\section{Materials and methods}

\subsection{Materials and experimental design}

Tea (Camellia sinensis L.) fruit was collected from the Panban tea garden (Zhejiang, China) in December, 2012. The ground fruit peel was treated with ethanol, followed by water extraction. A central composite design was applied and RSM was used to determine the optimum conditions for water extraction of total polysaccharide from ground fruit peel. After extraction with ethanol, centrifugation, and dialysis to give crude polysaccharides, the extract was further fractionated by ethanol at concentrations of $0 \%, 20 \%, 40 \%$, and $60 \%$.

\subsection{Composition analysis}

Neutral sugar content was measured by the anthrone-sulfuric acid method (Morris, 1948) using D-glucose as a standard reference. High-performance liquid chromatography (HPLC) equipment and Fourier transform infrared spectroscopy (FTIR) were used to identify the chemical compositions.

\subsection{Antioxidant capacity and $\alpha$-glucosidase in- hibitory activity}

2,2'-Azinobis(3-ethylbenzothiazoline-6-sulfonic acid) diammonium salt (ABTS) assay was carried out according to the method of Cai et al. (2004). The ferric-reducing antioxidant power (FRAP) assay was performed according to the modified method of Benzie and Strain (1999). The $\alpha$-glucosidase inhibitory activity of the tea fruit peel extracts was determined according to the method described by Apostolidis and Lee (2010) with slight modification.

Detailed materials and methods are described in Data S1.

\section{Results and discussion}

RSM was used to evaluate the effects of multiple factors and their interactions on one or more response variables, and to find the optimum combination of factor levels (Ballard et al., 2009). The second-order polynomial model was expressed by the following quadratic equation:

$$
\begin{aligned}
Y= & 4.65+0.39 X_{1}+0.26 X_{2}+0.053 X_{3}- \\
& 0.019 X_{1} X_{2}+0.030 X_{1} X_{3}-0.038 X_{2} X_{3}- \\
& 0.63 X_{1}^{2}-0.13 X_{2}^{2}+0.12 X_{3}^{2},
\end{aligned}
$$

where $Y$ is yield, $X_{1}$ is extraction temperature, $X_{2}$ is extraction time, and $X_{3}$ is liquid/solid ratio.

Analysis of variance (ANOVA) analysis of the quadratic regression models for TFPP yield showed that the model was highly significant $(P<0.01)$ with an $F$-value of 11.05 (Table 1). The $P$-value of 0.891 for "lack of fit" implied that it was not significantly relevant to the pure error (Jiang et al., 2011). The determination coefficient $\left(R^{2}\right)$ and adjusted coefficient $\left(R_{\mathrm{a}}^{2}\right)$ were 0.9087 and 0.8265 , respectively, indicating the model equation was adequate for 
predicting the extraction yield of TFPP within the range of experimental variables. The significance of the regression coefficients was examined by $F$-test. Accordingly, the extraction temperature $\left(X_{1}\right)$, extraction time $\left(X_{2}\right)$, and a quadratic term of extraction temperature $\left(X_{1}^{2}\right)$ were significant $(P<0.01)$, while other variables were not $(P>0.05)$.

Table 1 ANOVA for the effects of time, temperature, and liquid/solid ratio on TFPP using a quadratic response surface model

\begin{tabular}{lcrcrr}
\hline \multicolumn{1}{c}{ Source } & SS & DF & MS & $F$-value & $P r>F$ \\
\hline Model & 4.370 & 9 & 0.490 & 11.050 & $0.0004^{\mathrm{a}}$ \\
$X_{1}$ & 1.520 & 1 & 1.520 & 34.700 & $0.0002^{\mathrm{a}}$ \\
$X_{2}$ & 0.670 & 1 & 0.670 & 15.260 & $0.0029^{\mathrm{a}}$ \\
$X_{3}$ & 0.028 & 1 & 0.028 & 0.640 & 0.4421 \\
$X_{1} X_{2}$ & $2.846 \times 10^{-3}$ & 1 & $2.846 \times 10^{-3}$ & 0.065 & 0.8041 \\
$X_{1} X_{3}$ & $7.268 \times 10^{-3}$ & 1 & $7.268 \times 10^{-3}$ & 0.170 & 0.6926 \\
$X_{2} X_{3}$ & 0.012 & 1 & 0.012 & 0.270 & 0.6148 \\
$X_{1}^{2}$ & 1.110 & 1 & 1.110 & 25.270 & $0.0005^{\mathrm{a}}$ \\
$X_{2}^{2}$ & 0.050 & 1 & 0.050 & 1.130 & 0.3122 \\
$X_{3}^{2}$ & 0.042 & 1 & 0.042 & 0.960 & 0.3497 \\
Residual & 0.440 & 10 & 0.044 & & \\
Lack of fit & 0.100 & 5 & 0.021 & 0.310 & 0.8901 \\
Pure error & 0.340 & 5 & 0.067 & & \\
Cor total & 4.800 & 19 & & & \\
\hline$P<0.05 .5 S:$ & 0.54 & &
\end{tabular}

${ }^{\mathrm{a}} P<0.05$. SS: sum of square; DF: degree of freedom; MS: mean square; $X_{1}$ : extraction temperature; $X_{2}$ : extraction time; $X_{3}$ : liquid/ solid ratio

Fitted response surface plots for the model were established, with the shape of the contour plots indicating the significance of interactions between variables. A circular contour plot suggests that the interaction between the related variables is negligible, while an elliptical contour plot indicates that interaction is significant (Muralidhar et al., 2001). The response surface plots and contour plots (Fig. 1) were generated using Design-Expert, and describe the interaction between extraction time and temperature on TFPP yield under a constant liquid/solid ratio of $20(\mathrm{v} / \mathrm{w})$. Solid-liquid extraction is a mass transport phenomenon in which solid contained in a matrix migrates into a solvent brought into contact with the matrix (Shi et al., 2005). Corrales et al. (2009) hypothesized that the extraction temperature affects the mass transport phenomenon by inducing changes in diffusion coefficients. In this study, both the extraction time and extraction temperature had a significant impact on yields. A slight increase in the TFPP yield was observed with a longer extraction time. The peak yield of TFPP was reached around $75^{\circ} \mathrm{C}$, and higher or lower temperatures led to an inferior output.

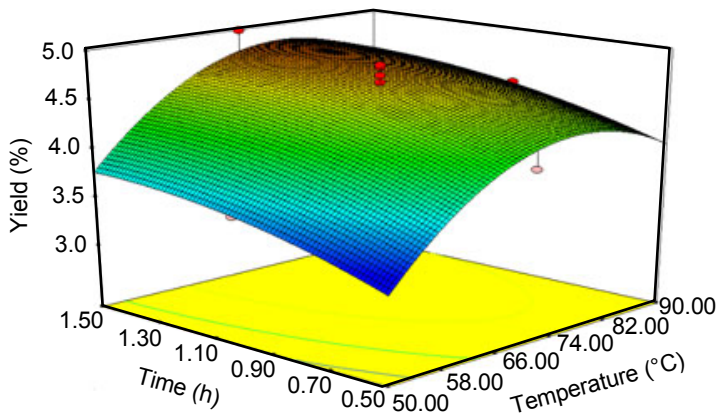

Fig. 1 Response surface plots of yield of total polysaccharides as affected by extraction time and extraction temperature

Liquid/solid ratio was set to $20(\mathrm{v} / \mathrm{w})$

Based on the model, the optimum extraction conditions for the maximum predicted yield of TFPPs $(4.98 \%)$ were a liquid/solid ratio of $20(\mathrm{v} / \mathrm{w})$, an extraction time of $90 \mathrm{~min}$, and an extraction temperature of $70^{\circ} \mathrm{C}$. The yield of polysaccharides extracted from the fruit peel was considerably higher than that extracted from seeds of Plantago asiatica L. (2.47\%) (Ye et al., 2011) and lower than that extracted from seeds of Arachis hypogaea (8.28\%) (Shen et al., 2010), indicating that tea fruit peel could be used as a resource for development of polysaccharide-enriched extracts.

The crude TFPP was further fractionated using ethanol at concentrations of $0 \%, 20 \%, 40 \%$, and $60 \%$. The chemical compositions of the fractionated TFPPs are presented in Table 2. Notably, TFPP-Crude contained the most protein $(14.25 \%)$ and uronic acid $(68.96 \%)$. TFPP-60 had the highest content of neutral sugar $(23.00 \%)$, but the lowest content of uronic acid (46.42\%). Monosaccharide composition analyzed by HPLC (Fig. 2) revealed that all the fractions contained seven monosaccharides (rhamnose, mannose, glucose, galactose, arabinose, xylose, and fucose) with different molar ratios. The TFPPs were a kind of seromucoid multi-mixture composed of multiple components (Table 2 and Fig. 2), which may create differences in primary or even high level structure, and affect their bioactivities (Srivastava and Kulshreshtha, 1989). 
Table 2 Chemical compositions of fractionated TFPPs

\begin{tabular}{|c|c|c|c|c|c|c|c|}
\hline Sample & \multicolumn{2}{|c|}{ Yield (\%) } & \multicolumn{2}{|l|}{ Protein $(\%)$} & Neutral sugar (\%) & \multicolumn{2}{|c|}{ Uronic acid (\%) } \\
\hline TFPP-Crude & \multicolumn{2}{|c|}{$1.07 \pm 0.21^{\mathrm{e}}$} & \multicolumn{2}{|l|}{$14.25 \pm 0.11^{\mathrm{a}}$} & $15.69 \pm 0.52^{\mathrm{b}}$ & \multicolumn{2}{|c|}{$68.96 \pm 2.25^{\mathrm{a}}$} \\
\hline TFPP-0 & \multicolumn{2}{|c|}{$69.16 \pm 0.35^{\mathrm{a}}$} & \multicolumn{2}{|l|}{$13.27 \pm 0.09^{\mathrm{b}}$} & $12.07 \pm 0.49^{\mathrm{c}}$ & \multicolumn{2}{|c|}{$65.52 \pm 1.12^{\mathrm{b}}$} \\
\hline TFPP-20 & \multicolumn{2}{|c|}{$4.00 \pm 0.02^{\mathrm{d}}$} & \multicolumn{2}{|c|}{$3.62 \pm 0.11^{\mathrm{e}}$} & $11.74 \pm 2.79^{\mathrm{c}}$ & \multicolumn{2}{|c|}{$56.31 \pm 0.34^{\mathrm{c}}$} \\
\hline TFPP-40 & \multicolumn{2}{|c|}{$14.80 \pm 0.19^{\mathrm{b}}$} & \multicolumn{2}{|c|}{$6.29 \pm 0.06^{\mathrm{c}}$} & $13.65 \pm 0.34^{\mathrm{bc}}$ & \multicolumn{2}{|c|}{$51.72 \pm 2.08^{\mathrm{d}}$} \\
\hline TFPP-60 & \multicolumn{2}{|c|}{$12.04 \pm 0.04^{\mathrm{c}}$} & \multicolumn{2}{|l|}{$5.68 \pm 0.02^{\mathrm{d}}$} & $23.00 \pm 0.12^{\mathrm{a}}$ & \multicolumn{2}{|c|}{$46.42 \pm 1.09^{\mathrm{e}}$} \\
\hline Sample & Rhamnose (\%) & Mannose (\%) & Glucose (\%) & Galactose (\%) & 6) Arabinose (\%) & Xylose (\%) & Fucose $(\%)$ \\
\hline TFPP-Crude & 1.03 & 0.66 & 0.54 & 2.25 & 1.63 & 0.19 & 3.70 \\
\hline TFPP-0 & 1.17 & 0.84 & 0.77 & 1.72 & 1.15 & 0.22 & 4.13 \\
\hline TFPP-20 & 0.12 & 0.38 & 0.09 & 1.51 & 0.91 & 0.54 & 6.45 \\
\hline TFPP-40 & 0.07 & 1.03 & 0.36 & 3.21 & 1.91 & 0.24 & 3.19 \\
\hline TFPP-60 & 0.27 & 0.84 & 0.96 & 2.86 & 3.07 & 0.44 & 1.56 \\
\hline
\end{tabular}

${ }^{\mathrm{a}-\mathrm{e}}$ Means $( \pm \mathrm{SD})$ with the same letter are not significantly different $(P>0.05)$. The yield of TFPP is expressed as dried weight percent; the compositions of protein, neutral sugar, and uronic acid are expressed as weight percent; and the others are expressed as mole percent
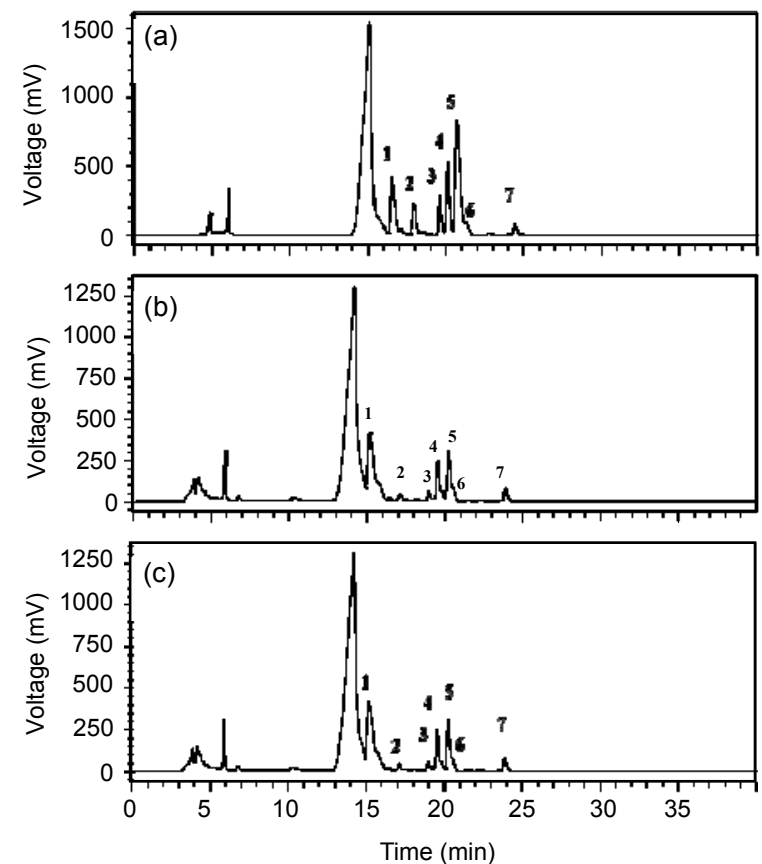
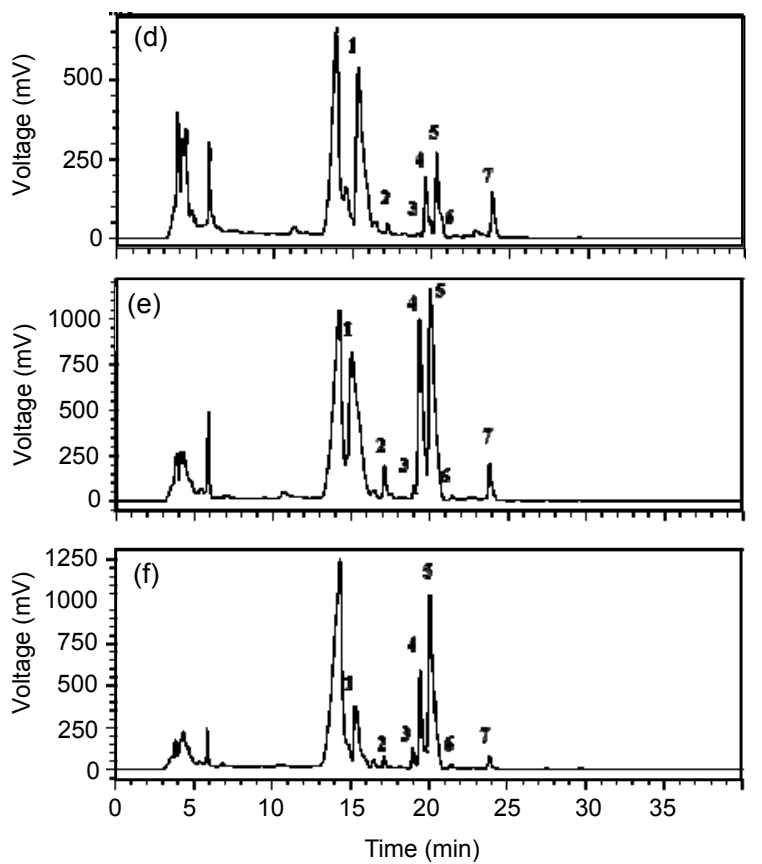

Fig. 2 HPLC chromatograms of monosaccharides in neutral sugars of the isolated TFPPs

(a) Standard mixture; (b) TFPP-Crude; (c) TFPP-0; (d) TFPP-20; (e) TFPP-40; (f) TFPP-60. Peak 1: rhamnose; Peak 2: mannose; Peak 3: glucose; Peak 4: galactose; Peak 5: arabinose; Peak 6: xylose; Peak 7: fucose

FTIR is typically used for the qualitative measurement of organic functional groups, especially $\mathrm{O}-\mathrm{H}$, $\mathrm{N}-\mathrm{H}$, and $\mathrm{C}=\mathrm{O}$ (Qian et al., 2009). All four polysaccharides demonstrated absorption near 3400 and $3930 \mathrm{~cm}^{-1}$, the stretching vibration regions of $\mathrm{O}-\mathrm{H}$ and saturated $\mathrm{C}-\mathrm{H}$, respectively (Fig. 3). The prominent absorption bands of the four polysaccharides in the range $1000-1200 \mathrm{~cm}^{-1}$ suggested that they all had a pyranose ring (Ding et al., 2010). A stretching peak appeared at around $1620 \mathrm{~cm}^{-1}$ with a weak peak at around $1418 \mathrm{~cm}^{-1}$, suggesting the presence of carboxyl groups. A small absorption peak at about $890 \mathrm{~cm}^{-1}$ could be associated with $\beta$-glycoside linkages between the sugar units. This may suggest that the TFPPs belong to $\beta$-type heteropolysaccharides with a pyran group. However, a difference that appeared at nearly $1500 \mathrm{~cm}^{-1}$ (Figs. 3a and 3b) was the absorption of the stretching vibration of $\mathrm{C}=\mathrm{O}$, indicating the existence of uronic acid, which strengthened our conclusion from the results in Table 2 that TFPP-Crude and TFPP-0 contained the most uronic acid. 

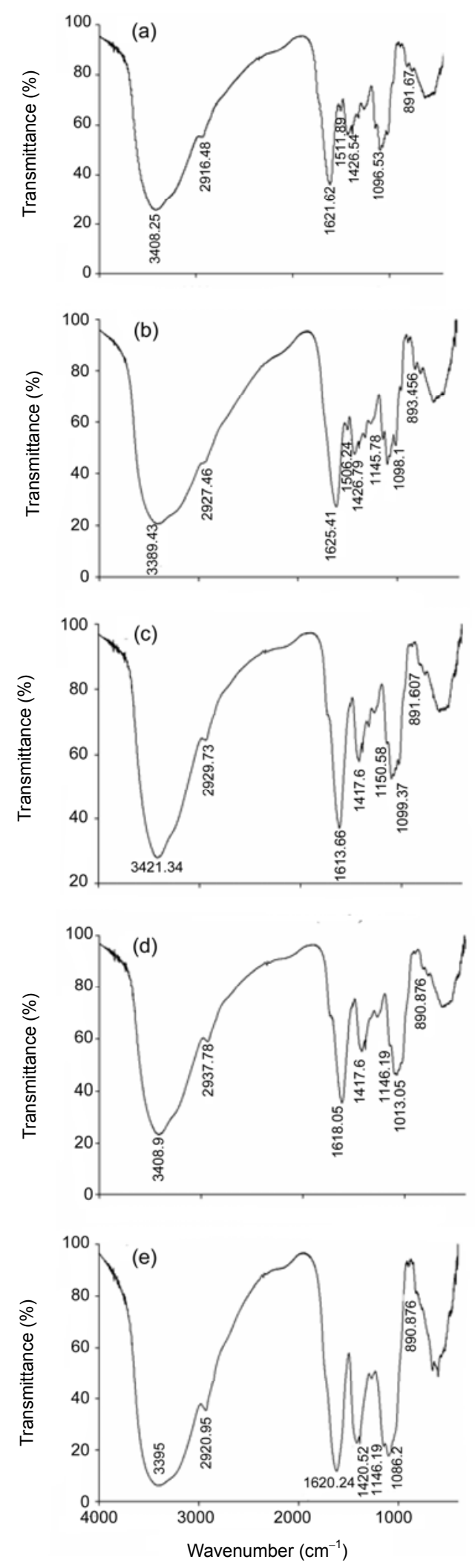

Fig. 3 FTIR spectra of TFPP-Crude (a), TFPP-0 (b), TFPP-20 (c), TFPP-40 (d), and TFPP-60 (e)
The ABTS assay is often used in evaluating the total antioxidant ability of single compounds or complex mixtures from various plants, where an electron transfer process is involved (Huang et al., 2008). In the present study, the scavenging ability of the TFPPs on ABTS free radicals was determined (Fig. 4a). The scavenging ability of the TFPPs correlated positively with their increasing concentrations, but was significantly weaker than that of butylated hydroxytoluene (BHT). At a concentration of $1000 \mu \mathrm{g} / \mathrm{ml}$, the order of scavenging abilities of all tested samples was: TFPPCrude $(90.72 \%)>$ BHT $(87.55 \%)>$ TFPP-0 $(77.68 \%)>$ TFPP-60 (53.81\%)>TFPP-40 (44.27\%)>TFPP-20 (35.67\%). The results suggest that the TFPPs had a strong scavenging activity on ABTS. Also, as the ABTS model can be used to assess the scavenging activity for both polar and non-polar samples (Kaviarasan et al., 2007), the strong scavenging activity of TFPPCrude might be attributable to its total content of protein, neutral sugar, and uronic acid (98.90\% TFPPCrude, $90.86 \%$ TFPP-0, 75.10\% TFPP-60, 71.67\% TFPP-20, and $71.66 \%$ for TFPP-40).

FRAP measures the antioxidant effect of substances in the reaction medium by their reducing ability, which is considered as the ability of a natural antioxidant to donate electrons (Shi et al., 2009). The metal chelating activity of polysaccharides increased with increasing concentrations used in the test (Fig. 4b). The chelating ability decreased in the order BHT> TFPP-60>TFPP-40>TFPP-Crude $>$ TFPP-20 $>$ TFPP- 0 at the concentration of $1000 \mu \mathrm{g} / \mathrm{ml}$. The results suggest that the TFPPs had a strong reducing ability on FRAP, and that the strong reducing ability of TFPP-60 might be attributable to its high content of neutral sugar.

It has been recognized that metal chelating ability could be involved in antioxidant activity and may affect other functions that contribute to antioxidant activity. The antioxidant activity of plant polysaccharides may be influenced by lots of factors, such as their structure, molecular weight, and chemical composition (Chen et al., 2008). For example, hydroxyl groups of monosaccharides in a polysaccharide are considered to be a significant factor in affecting free radical scavenging ability, due to their potential to donate hydrogen (Tian et al., 2011). Many studies have revealed that oxidative stress is associated with a wide range of diseases (Finkel and Holbrook, 2000; 
Rains and Jain, 2011). Thus, the antioxidant activity of bioactive compounds can be considered as an important index by which their potential benefits for human health can be evaluated (Wang et al., 2011). The chelating effect of TFPPs on ferrous ions may to some extent affect the other activities of scavenging free radicals to protect organisms against oxidative damage (Ye et al., 2011).
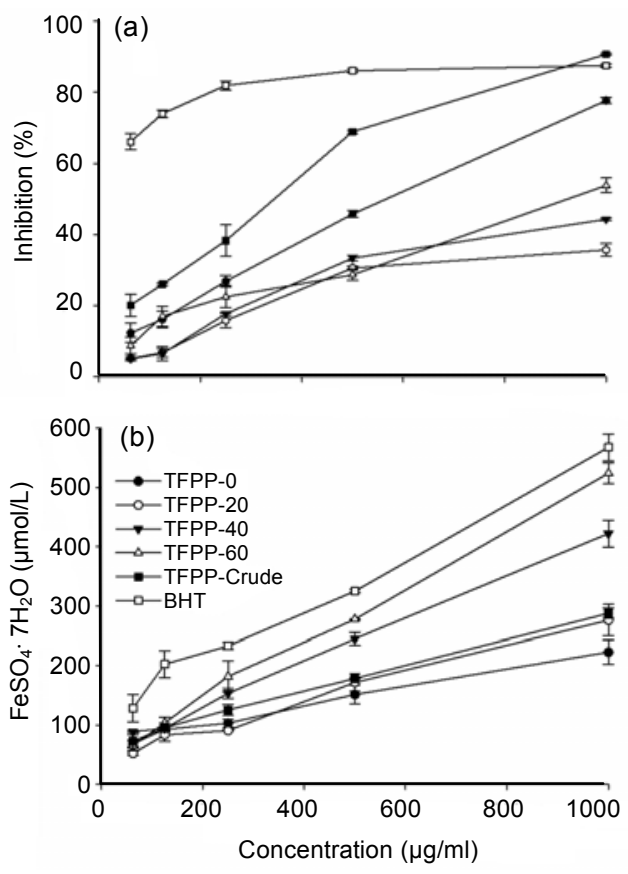

Fig. 4 Antioxidant activities of TFPPs evaluated by ABTS (a) and FRAP (b) assays

Data are expressed as mean \pm SD $(n=3)$

$\alpha$-Glucosidase, a key enzyme for carbohydrate digestion, has been recognized as a therapeutic target for modulation of postprandial hyperglycemia, the earliest metabolic abnormality in type $2 \mathrm{DM}$ (Krentz and Bailey, 2005). Previous reports have shown that polysaccharides from a wide range of food or medical plant sources could be effective $\alpha$-glucosidase inhibitors (Kwon et al., 2008; Shibano et al., 2008; Kim et al., 2010). In this study, the inhibitory effects of TFPPs on $\alpha$-glucosidase were investigated. All four TFPPs exhibited much stronger inhibitory effects on $\alpha$-glucosidase than did acarbose at a concentration higher than $250 \mu \mathrm{g} / \mathrm{ml}$ (Fig. 5). The $\alpha$-glucosidase inhibitory effect of TFPP- 0 increased rapidly from $61.0 \%$ to $93.8 \%$ as the concentration increased from 62.5 to $500.0 \mu \mathrm{g} / \mathrm{ml}$. The half maximal inhibitory concentration $\left(\mathrm{IC}_{50}\right)$ values of TFPP-40, TFPP-60, TFPP-20, and acarbose estimated from Fig. 5 were $126.9,452.5,483.3$, and $870.2 \mu \mathrm{g} / \mathrm{ml}$, respectively. This indicates that the inhibition effects of TFPPs on $\alpha$-glucosidase were notably better than that of acarbose. TFPP-0 showed the strongest inhibition of $\alpha$-glucosidase, with a maximum of $97 \%$, which was mainly attributable to its high contents of protein and uronic acid (Table 2). Our results indicated that TFPPs could act as both antioxidants and $\alpha$-glucosidase inhibitors, and have potential to be used in the prevention of type 2 DM. Further studies on the inhibitory effect of TFPPs on $\alpha$-glucosidase in in vivo models are in progress.

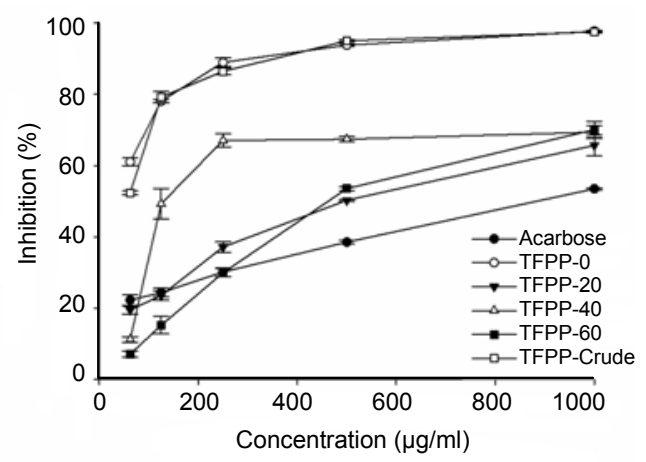

Fig. 5 Inhibition of $\alpha$-glucosidase by TFPPs Data are expressed as mean $\pm \mathrm{SD}(n=3)$

Based on the results obtained, we conclude that tea fruit peel is a potentially valuable renewable bioresource for the development of polysaccharide antioxidants. TFPPs were found to be acid protein-bound heteropolysaccharides, and not only to possess remarkable scavenging activity on ABTS and reducing activity, but also to exhibit excellent inhibitory potential against $\alpha$-glucosidase in vitro. Protein, neutral sugar, and uronic acid are suggested to have at least some positive effects on the biological behavior of TFPPs. Further studies on the purified TFPPs should be carried out to help illustrate more clearly the structure/activity relationship of the polysaccharides.

\section{Compliance with ethics guidelines}

Yue-fei WANG, Jie WANG, Jing WU, Ping XU, Yi-qi WANG, Jun-jie GAO, and Danielle HOCHSTETTER declare that they have no conflict of interest.

This article does not contain any studies with human or animal subjects performed by any of the authors. 


\section{References}

Apostolidis, E., Lee, C., 2010. In vitro potential of Ascophyllum nodosum phenolic antioxidant-mediated $\alpha$-glucosidase and $\alpha$-amylase inhibition. J. Food Sci., 75(3): H97-H102. [doi:10.1111/j.1750-3841.2010.01544.x]

Ballard, T.S., Mallikarjunan, P., Zhou, K., et al., 2009. Optimizing the extraction of phenolic antioxidants from peanut skins using response surface methodology. $J$. Agric. Food Chem., 57(8):3064-3072. [doi:10.1021/jf803 0925]

Benzie, I.F.F., Strain, J.J., 1999. Ferric reducing/antioxidant power assay: direct measure of total antioxidant activity of biological fluids and modified version for simultaneous measurement of total antioxidant power and ascorbic acid concentration. Meth. Enzymol., 299:15-27. [doi:10.1016/ S0076-6879(99)99005-5]

Cai, Y., Luo, Q., Sun, M., et al., 2004. Antioxidant activity and phenolic compounds of 112 traditional Chinese medicinal plants associated with anticancer. Life Sci., 74(17): 2157-2184. [doi:10.1016/j.lfs.2003.09.047]

Çam, M., Aaby, K., 2010. Optimization of extraction of apple pomace phenolics with water by response surface methodology. J. Agric. Food Chem., 58(16):9103-9111. [doi:10.1021/jf1015494]

Chen, H.X., Zhang, M., Qu, Z.S., et al., 2008. Antioxidant activities of different fractions of polysaccharide conjugates from green tea (Camellia sinensis). Food Chem., 106(2):559-563. [doi:10.1016/j.foodchem.2007. 06.040]

Chen, Y.G., Shen, Z.J., Chen, X.P., 2009. Evaluation of free radicals scavenging and immunity-modulatory activities of Purslane polysaccharides. Int. J. Biol. Macromol., 45(5):448-452. [doi:10.1016/j.ijbiomac.2009.07.009]

Corrales, M., García, A.F., Butz, P., et al., 2009. Extraction of anthocyanins from grape skins assisted by high hydrostatic pressure. J. Food Eng., 90(4):415-421. [doi:10.1016/j. jfoodeng.2008.07.003]

Ding, X., Tang, J., Cao, M., et al., 2010. Structure elucidation and antioxidant activity of a novel polysaccharide isolated from Tricholoma matsutake. Int. J. Biol. Macromol., 47(2):271-275. [doi:10.1016/j.ijbiomac.2010. 04.010]

Finkel, T., Holbrook, N.J., 2000. Oxidants, oxidative stress and the biology of ageing. Nature, 408:239-247. [doi:10. 1038/35041687]

Grice, H.C., 1988. Safety evaluation of butylated hydroxyanisole from the perspective of effects on forestomach and oesophageal squamous epithelium. Food Chem. Toxicol., 26(8):717-723. [doi:10.1016/02786915(88)90072-5]

Huang, S.S., Huang, G.J., Ho, Y.L., et al., 2008. Antioxidant and antiproliferative activities of the four Hydrocotyle species from Taiwan. Bot. Stud., 49(4):311-322.

Jiang, C.X., Wang, M.C., Liu, J., et al., 2011. Extraction, preliminary characterization, antioxidant and anticancer activities in vitro of polysaccharides from Cyclina sinensis. Carbohyd. Polym., 84(3):851-857. [doi:10. 1016/j.carbpol.2010.11.027]

Kaviarasan, S., Naik, G.H., Gangabhagirathi, R., et al., 2007. In vitro studies on antiradical and antioxidant activities of fenugreek (Trigonella foenum graecum) seeds. Food Chem., 103(1):31-37. [doi:10.1016/j.foodchem.2006.05. 064]

Kim, J.S., Kwon, Y.S., Chun, W.J., et al., 2010. Rhus verniciflua Stokes flavonoid extracts have anti-oxidant, anti-microbial and $\alpha$-glucosidase inhibitory effect. Food Chem., 120(2):539-543. [doi:10.1016/j.foodchem.2009. 10.051]

Krentz, A.J., Bailey, C.J., 2005. Oral antidiabetic agents. Drugs, 65(3):385-411. [doi:10.2165/00003495-20056 5030-00005]

Kwon, Y.I., Apostolidis, E., Shetty, K., 2008. In vitro studies of eggplant (Solanum melongena) phenolics as inhibitors of key enzymes relevant for type 2 diabetes and hypertension. Bioresour. Technol., 99(8):2981-2988. [doi:10.1016/j. biortech.2007.06.035]

Lin, C.L., Wang, C.C., Chang, S.C., et al., 2009. Antioxidative activity of polysaccharide fractions isolated from Lycium barbarum Linnaeus. Int. J. Biol. Macromol., 45(2): 146-151. [doi:10.1016/j.ijbiomac.2009.04.014]

Ma, X.F., Li, H.Y., Wang, F., et al., 2011. Separation process and nutrient value analysis of sea buckthom. Acad. Period. Farm Prod. Process., (2):43-45 (in Chinese). [doi:10. 3969/jissn.1671-9646(X).2011.02.012]

Morris, D.L., 1948. Quantitative determination of carbohydrates with Dreywood's anthrone reagent. Science, 107(2775): 254-255. [doi:10.1126/science.107.2775.254]

Moskovitz, J., Yim, M.B., Chock, P.B., 2002. Free radicals and disease. Arch. Biochem. Biophys., 397(2):354-359. [doi:10.1006/abbi.2001.2692]

Muralidhar, R.V., Chirumamila, R.R., Marchant, R., et al., 2001. A response surface approach for the comparison of lipase production by Candida cylindracea using two different carbon sources. Biochem. Eng. J., 9(1):17-23. [doi:10.1016/S1369-703X(01)00117-6]

Praticò, D., Delanty, N., 2000. Oxidative injury in diseases of the central nervous system: focus on Alzheimer's disease. Am. J. Med., 109(7):577-585. [doi:10.1016/S0002-9343 (00)00547-7]

Qian, J.Y., Chen, W., Zhang, W.M., et al., 2009. Adulteration identification of some fungal polysaccharides with SEM, XRD, IR and optical rotation: a primary approach. Carbohyd. Polym., 78(3):620-625. [doi:10.1016/j.carbpol. 2009.05.025]

Rains, J.L., Jain, S.K., 2011. Oxidative stress, insulin signaling, and diabetes. Free Radic. Biol. Med., 50(5):567-575. [doi:10.1016/j.freeradbiomed.2010.12.006]

Shen, J.F., Kang, H.Q., Chen, Y.Q., et al., 2010. Polysaccharides from fruit shell of Camellia oleifera Abel: extraction and antioxidation activity. J. Chin. Cereals Oils Assoc., 25(8):51-54 (in Chinese).

Shi, J., Nawaz, H., Pohorly, J., et al., 2005. Extraction of polyphenolics from plant material for functional 
foods-engineering and technology. Food Rev. Int., 21(1):139-166. [doi:10.1081/FRI-200040606]

Shi, J.Y., Gong, J.Y., Liu, J.E., et al., 2009. Antioxidant capacity of extract from edible flowers of Prunus mume in China and its active components. LWT-Food Sci. Technol., 42(2):477-482. [doi:10.1016/j.lwt.2008.09.008]

Shibano, M., Kakutani, K., Taniguchi, M., et al., 2008. Antioxidant constituents in the dayflower (Commelina communis L.) and their $\alpha$-glucosidase-inhibitory activity. J. Nat. Med., 62(3):349-353. [doi:10.1007/s11418-0080244-1]

Srivastava, R., Kulshreshtha, D.K., 1989. Bioactive polysaccharides from plants. Phytochemistry, 28(11):2877-2883. [doi:10. 1016/0031-9422(89)80245-6]

Tian, L.M., Zhao, Y., Guo, C., et al., 2011. A comparative study on the antioxidant activities of an acidic polysaccharide and various solvent extracts derived from herbal Houttuynia cordata. Carbohyd. Polym., 83(2): 537-544. [doi:10.1016/j.carbpol.2010.08.023]

Wang, Y., Bian, X., Park, J., et al., 2011. Physicochemical properties, in vitro antioxidant activities and inhibitory potential against $\alpha$-glucosidase of polysaccharides from Ampelopsis grossedentata leaves and stems. Molecules, 16(9):7762-7772. [doi:10.3390/molecules 16097762]

Wang, Y.F., Huang, S.R., Shao, S.H., et al., 2012. Studies on bioactivities of tea (Camellia sinensis L.) fruit peel extracts: antioxidant activity and inhibitory potential against $\alpha$-glucosidase and $\alpha$-amylase in vitro. Ind. Crops Prod., 37(1):520-526. [doi:10.1016/j.indcrop.2011.07.031]

$\mathrm{Xu}, \mathrm{P} ., \mathrm{Bao}, \mathrm{J}$. , Gao, J., et al., 2012. Optimization of extraction of phenolic antioxidants from tea (Camellia sinensis L.) fruit peel biomass using response surface methodology. BioResources, 7(2):2431-2443.

Xu, W.T., Zhang, F.F., Luo, Y.B., et al., 2009. Antioxidant activity of a water-soluble polysaccharide purified from Pteridium aquilinum. Carbohyd. Res., 344(2):217-222. [doi:10.1016/j.carres.2008.10.021]

Yang, X.M., Yu, W., Ou, Z.P., et al., 2009. Antioxidant and immunity activity of water extract and crude polysaccharide from Ficus carica L. fruit. Plant Food Hum. Nutr., 64(2):167-173. [doi:10.1007/s11130-009-0120-5]

Ye, C.L., Hu, W.L., Dai, D.H., 2011. Extraction of polysaccharides and the antioxidant activity from the seeds of Plantago asiatica L. Int. J. Biol. Macromol., 49(4):466-470. [doi:10.1016/j.ijbiomac.2011.05.026]

Zhu, K.X., Nie, S.P., Li, C., et al., 2013. A newly identified polysaccharide from Ganoderma atrum attenuates hyperglycemia and hyperlipidemia. Int. J. Biol. Macromol., 57:142-150. [doi:10.1016/j.ijbiomac.2013.03.009]

\section{List of electronic supplementary materials}

Data S1 Materials and methods

\section{中文㩯要:}

\section{本文题目: 茶果皮多糖理化性质、体外抗氧化活性及对 $\boldsymbol{\alpha}$-葡萄糖草酶的抑制作用}

In vitro antioxidant activity and potential inhibitory action against $\alpha$-glucosidase of polysaccharides from fruit peel of tea (Camellia sinensis L.)

研究目的: 利用响应面优化茶果皮多糖 (TFPP) 提取条件, 用乙醇分级分段得到 4 个多糖组分 (TFPP-0、 TFPP-20、TFPP-40 和 TFPP-60），并研究其理化性质、抗氧化活性和对 $\alpha$-葡萄糖苷酶抑制作 用, 为综合高效利用茶果皮多糖资源提供理论基础。

创新要点: 1. 首次将茶果皮作为一种潜在生物资源研究; 2 . 首次研究茶果皮多糖这一功能成分; 3 . 将工 艺优化、理化性质和生物活性结合研究。

研究方法: 三因素三水平响应面设计 (见表 1), 傅里叶转换红外光谱法分析茶果皮粗多糖的功能团结 构（见图 3），高效液相色谱法检测单糖组分（见表 2），2,2'-氨基-二(3-乙基-苯并噻唑啉-6磺酸)二铵盐（ABTS）自由基清除法（见图 4a）和铁离子还原能力法（FRAP）（见图 4b） 分析茶果皮多糖抗氧化活性。

重要结论: 1. 茶果皮多糖是一种水溶性的酸性杂多糖蛋白复合物; 2. 乙醇分级是一种有效多糖分离手段; 3. 茶果皮多糖具有出色的生物活性; 4. 茶果皮资源可以作为一种可再生生物资源进行深度的 开发。

关键词组：茶果皮；多糖；响应面；抗氧化； $\alpha$-葡萄糖苷酶抑制 